\title{
How should the management of ovarian masses in children?
}

\author{
Yusuf Atakan Baltrak ${ }^{1}$, Seniha Esin Söğüt ${ }^{1}$, Arzu Yavuz ${ }^{2}$, Onursal Varlikli1, Hasan Terzi² \\ ${ }^{1}$ Department of Pediatric Surgery, University of Health Science, Kocaeli Derince Training and Research Hospital, Derince, Kocaeli, Turkey \\ ${ }^{2}$ Department of Obstetrics and Gynecology, University of Health Science, Kocaeli Derince Training and Research Hospital, Derince, Kocaeli, Turkey
}

Received: 2020-09-16.

Accepted: 2020-11-08

This work is licensed under

Creative Commons Attribution 4.0

International License

J Clin Med Kaz 2020; 6(60):88-92

Corresponding author:

Yusuf Atakan Baltrak.

E-mail: dratakanbaltrak@gmail.com;

ORCID: 0000-0001-8457-5108

\section{Abstract}

Introduction: Prevalence of ovarian masses in children increase due to easy access to imaging techniques. There are conflicting views about evaluation and classification of ovarian masses for neoplasia in such age group in the literature.

Material and methods: The patients who were monitored and treated because of ovarian mass in pediatric surgery and obstetrics and gynaecology clinics were reviewed retrospectively. Demographic data, symptoms, dimensions and lateralization of the mass, serum tumour markers, histopathological evaluation results, and treatment outcomes of the patients enrolled in were recorded. Ovarian masses of the participants were divided into two groups as non-neoplastic group (NNG) and neoplastic group (NG) depending on imaging techniques, serum tumour markers and histopathological analysis results. Results were statistically reviewed.

Results: There was not any statistical difference between NG and NNG for age, body mass index, mass diameter, initial symptoms, and mass lateralization ( $p>0.05$ ). Review of ovarian masses reported by imaging techniques revealed that pure cystic appearance was statistically significant for NNG $(p=0.012)$. Duration of the surgery and hospitalization were detected shorter in NNG treated laparoscopically $(p=0.023)$.

Conclusion: Surgical treatment of ovarian masses in children should be ovarian protective as much as possible. However, there is not any reliable and proven marker that may differentiate a benign ovarian mass from a malignant ovarian mass in paediatric patients like adult population. A detailed medical history, physical examination, imaging methods, and adequate tumour markers should be used for preoperative evaluation of adnexial masses.

Key words: child, malignancy, ovarian neoplasms, surgery

\section{Introduction}

Annual incidence of ovarian masses in the paediatric age group is predicted as 2.6 per 100,000 girls [1]. Neoplastic ovarian masses consist of $1 \%$ to $2 \%$ of all paediatric malignancies, and of $20 \%$ if all ovarian masses in the same age group [2]. Prevalence of neoplasia in ovarian masses in the children is rare when compared with adults; however, ovarian masses constitutes $60 \%$ to $70 \%$ do all gynaecological malignancies [3]. Easy access to imaging tests and common use of minimally invasive procedures has facilitated diagnosis and treatment of ovarian masses. Minimally invasive procedures become widespread for differential diagnosis and surgical treatment of ovarian tumours due to shorter duration of surgery and hospitalization, decrease in pain and cosmetic concerns $[4,5]$.

The aim of the present study was to determine epidemiological, demographic, clinical presentation and management of the patients who were monitored and treated due to ovarian mass in gynaecology and pediatric surgery clinics of our hospital, by comparing neoplastic group (NG) and non neoplastic group (NNG) ovarian mass outcomes.

\section{Material and methods}

The patients who were diagnosed with ovarian mass, monitored and treated in Paediatric Surgery and Gynaecology Clinics of Kocaeli Derince Training and Research Hospital within Health Sciences University between January 2015 and January 2020 were reviewed retrospectively. Approval by ethical committee of Kocaeli Derince Training and Research Hospital was obtained for this retrospective study with approval number of 44 on May, 28th, 2020. Data were obtained from medical files of the patients in digital filling system of the hospital. Patients with deficient information in the files, and those diagnosed with another condition during follow-up and treatment were excluded from the study. Demographic data, symptoms, 
dimensions and lateralization of the mass, serum tumour markers, his to pathological evaluation results, and treatment outcomes of the patients enrolled in were recorded.

Ovarian masses of the participants were divided into two groups as non-neoplastic group (NNG) and neoplastic group (NG) depending on imaging techniques, serum tumour markers and his to pathological analysis results. Patients diagnosed with para ovarian cyst, corpus luteum cyst, ovarian endometriosis cyst, hemorrhagic or follicular cyst, and paratubal cyst were accepted as NNG. Data were analyzed through SPSS 24.0 (IBM Corp, Armonk, NY) software. Normally distributed quantitative variables were expressed in mean standard distribution; and variables that do not distribute normally were expressed in median (range). Mann-Whitney $U$ test was used to detect any differences in quantitative variables between the groups.
Comparison of categorical variables was performed by chisquare test. The significance level was accepted as $\mathrm{p}<0.05$.

\section{Results}

Sixty two patients were enrolled in to the study. The patients were divided in to two groups as $\mathrm{NG}$ and $\mathrm{NNG}$ depending on tests and histopathological diagnosis results. Forty eight participants were included in NNG group whereas fourteen patients were evaluated in NG ovarian mass group. The most common complaint of referral was abdominal pain (43 patients; $69.3 \%$ ). Among referrals due to abdominal pain, $48 \%$ of the patients referred to emergency department. There was not any statistical difference between NG and NNG for age, body mass index, mass diameter, initial symptoms, and mass lateralization $(p>0.05)$. Patient characteristics depending on referral were summarized in Table 1.

Distribution of demographic features and symptoms

\begin{tabular}{|c|c|c|c|c|c|}
\hline \multicolumn{3}{|l|}{ Variable } & NG (n, \%) & NNG $(n, \%)$ & $\mathrm{p}$ \\
\hline \multicolumn{3}{|l|}{ Number $=62$} & $14(22.5)$ & $48(77.5)$ & \\
\hline \multicolumn{3}{|c|}{ Age (median) / (min-max) / year } & $11.5(8-16)$ & $12.7(9-17)$ & 0.486 \\
\hline \multicolumn{3}{|c|}{ Dimensions of the ovary (median) / (min-max) / cm } & $6.8(3.1-16.4)$ & $8.6(3.2-23.1)$ & 0.124 \\
\hline \multicolumn{3}{|c|}{$\mathrm{BMI}=\mathrm{kg} / \mathrm{m} 2(\operatorname{median}) /(\min -\max )$} & $21.4(18-28)$ & $20.9(17.6-27.5)$ & 0.342 \\
\hline \multirow[t]{5}{*}{ Symptom (n, \%) } & \multirow{2}{*}{$\begin{array}{l}\text { Abdominal Pain }=43 \\
(69.3)\end{array}$} & $\mathrm{ER}=21(48.8)$ & $3(6.9)$ & $18(41.8)$ & \multirow[t]{2}{*}{0.128} \\
\hline & & Polyclinic $=22(51.2)$ & $6(13.9)$ & $16(37.2)$ & \\
\hline & \multicolumn{2}{|c|}{ Abdominal Distension=13 $(16,1)$} & $6(9.6)$ & $7(11.2)$ & 0.254 \\
\hline & \multicolumn{2}{|c|}{ Routine examination $=5(8,0)$} & $3(4.8)$ & $2(3.2)$ & 0.123 \\
\hline & \multicolumn{2}{|c|}{ Puberty Praecox=1 $(1,6)$} & $1(1.6)$ & 0 & \\
\hline \multirow[t]{2}{*}{ Side (n, \%) } & \multicolumn{2}{|c|}{ Right $=36(58,0)$} & 7 & 29 & \multirow[t]{2}{*}{0.765} \\
\hline & \multicolumn{2}{|l|}{ Left $=26(42,0)$} & 7 & 19 & \\
\hline
\end{tabular}

*NG: Neoplastic Group **NNG: Non-euplastic Group

Table 2

Treatment outcomes of ovarian masses

\begin{tabular}{|c|c|c|c|c|}
\hline \multicolumn{2}{|l|}{ Variable (n, \%) } & \multirow{2}{*}{$\begin{array}{l}\text { NG } \\
6(28.5)\end{array}$} & \multirow{2}{*}{$\begin{array}{l}\text { NOG } \\
15(71.5)\end{array}$} & \multirow{2}{*}{$\begin{array}{l}p \\
0.017\end{array}$} \\
\hline Mass diameter (cm) & $>8 \mathrm{~cm}(21 ; 33.8)$ & & & \\
\hline & $<8 \mathrm{~cm}(41 ; 66.2)$ & $8(19.5)$ & $33(80.5)$ & 0.023 \\
\hline \multirow[t]{3}{*}{ Imaging } & Ultrasound=47 & $11(23.4)$ & $36(76.5)$ & 0.145 \\
\hline & Magnetic Resonance $=28$ & $10(35.7)$ & $18(64.2)$ & 0.321 \\
\hline & $\mathrm{CT}=12$ & $3(27.2)$ & $8(72.7)$ & 0.236 \\
\hline \multirow[t]{3}{*}{ Mass Appearance } & Pure cystic & 2 & 26 & $<0.001$ \\
\hline & Mixed & 5 & 11 & 0.342 \\
\hline & Solid & 9 & 9 & 0.808 \\
\hline \multirow[t]{2}{*}{ AFP } & Positive & 9 & 0 & \multirow[t]{2}{*}{$<0.001$} \\
\hline & Negative & 14 & 48 & \\
\hline \multirow[t]{2}{*}{ Beta HCG } & Positive & 9 & 0 & \multirow[t]{2}{*}{$<0.001$} \\
\hline & Negative & 14 & 48 & \\
\hline \multirow[t]{2}{*}{ LDH } & Positive & 8 & 1 & \multirow[t]{2}{*}{0.0032} \\
\hline & Negative & 14 & 34 & \\
\hline \multirow[t]{2}{*}{ CA 125} & Positive & 8 & 3 & \multirow[t]{2}{*}{0.0041} \\
\hline & Negative & 14 & 36 & \\
\hline \multicolumn{5}{|l|}{ Treatment } \\
\hline Conservative $=11$ & & 0 & 11 & \\
\hline \multirow[t]{2}{*}{ Aspiration/Cystectomy/Ovarian conservative surgery=34 } & Laparoscopic $=22$ & $3(8.8)$ & $19(55.8)$ & 0.001 \\
\hline & Laparotomy=12 & $4(11.7)$ & $8(23.5)$ & 0.256 \\
\hline \multirow[t]{2}{*}{ Oopherectomy=7 } & Laparoscopic $=0$ & 0 & 0 & \multirow[t]{2}{*}{0.001} \\
\hline & Laparotomy=7 & 6 & 1 & \\
\hline \multirow[t]{2}{*}{ Distortion $=10$} & Laparoscopic $=8$ & 0 & 8 & \multirow[t]{2}{*}{0.001} \\
\hline & Laparotomy=2 & 1 & 1 & \\
\hline \multirow[t]{2}{*}{ Surgery duration (minutes) } & Laparoscopic & $59.4 \pm 25.3$ & $73 \pm 34.5$ & 0.023 \\
\hline & Laparotomy & $73.2 \pm 17.8$ & $86 \pm 13.4$ & 0.165 \\
\hline \multirow[t]{2}{*}{ Hospitalization Duration (days) } & Laparoscopic & $3.4 \pm 1.6$ & $2.6 \pm 1.1$ & 0.024 \\
\hline & Laparotomy & $4.5 \pm 2.1$ & $3.7 \pm 1.3$ & 0.643 \\
\hline
\end{tabular}

*NG: Neoplastic Group **NNG: Non-euplastic Group 


\begin{tabular}{|l|l|l|l|l|}
\hline & Specificity & Sensitivity & PPV & NPV \\
\hline Ultrasound & $87.5 \%$ & $64.7 \%$ & $85.3 \%$ & $74.1 \%$ \\
\hline Pelvic MRI & $96.1 \%$ & $72.3 \%$ & $89.2 \%$ & $88.8 \%$ \\
\hline CT & $90 \%$ & $67.8 \%$ & $75.2 \%$ & $75 \%$ \\
\hline
\end{tabular}

*PPV: Positive Predicted Value **NPV: Negative Predictive Value

Dimensions of the ovarian mass decreased or mass disappeared in $11(22.9 \%)$ patients within NNG group without any procedure during follow-up (Table 2).

Review of cytology analysis reports of the patients in NNG group who had surgical procedure included four patients with corpus luteum cyst, four patients with follicle cyst, eight patients with hemorrhagic cyst and four patients with para-ovarian cyst.

All patients in the NG group were operated. When cytology analysis reports of the patients in NG group were reviewed, mature teratoma was reported in eleven patients, immature teratoma was detected in two patients, and mixed germ cell tumour was detected in one patient.

For differential diagnosis of the patients enrolled into the study, ultrasound and Doppler ultrasound were used in 47 patients, Magnetic Resonance was used in 28 patients, and Computed Tomography was used in 12 patients. All patients whom computed tomography was preferred have referred to emergency department due to abdominal pain. Review of ovarian masses reported by imaging techniques revealed that pure cystic appearance was statistically significant for NNG $(p=0.012)$. There was not any statistically significant difference for mixed and solid appearance of ovarian masses through imaging techniques between two groups $(p=0.345)$ (Table 2).

Evaluation of imaging test results along with his to pathological analysis results revealed sensitivity, specificity, positive predictive value, and negative predictive value of the ultrasound as $87.5 \%, 64.7 \%, 85.3 \%$, and $74.1 \%$, respectively. Furthermore, sensitivity, specificity, positive predictive value, and negative predictive value of pelvic MRI were 96.1\%, 72.3\%, $89.2 \%$, and $88.2 \%$, respectively. Sensitivity, specificity, positive predictive value, and negative predictive value of CT were $90 \%$, $67.8 \%, 75.2 \%$, and $75 \%$, respectively.

Comparison of AFP, beta HCG and LDH which are accepted as serum tumour marker in paediatric ovarian masses revealed that negative serum tumour marker values were significant in NNG group ( $\mathrm{p}=0.01$ ) (Table 2).

Fifty one patients diagnosed with ovarian mass were treated surgically. Urgent surgery was performed in 22 (43.1\%) patients whereas $29(56.8 \%)$ patients had the surgery under elective conditions. Among the patients operated under emergency conditions, 10 patients were operated due to preliminary diagnosis of ovarian torsion. Laparoscopic ovarian detorsion was performed in 8 patients whom ovarian torsion. Laparotomic oopherectomy was performed in 2 patients. Mature teratoma was detected in one patient after histopathological analysis of the patients who had laparotomic oopherectomy (Tables 1,2).

Among the patients who were treated surgically, aspiration, cystectomy or conservative procedures were performed in 34 patients whereas 7 patients had oopherectomy. Duration of the surgery and hospitalization was shorter in the patients in NNG treated laparoscopically $(p=0.023)$. There was not any statistically significant difference in duration of surgery and hospitalization in the patients who had laparotomy $(\mathrm{p}=0.165)$ (Table 2).

\section{Discussion}

The most common clinical presentation of ovarian masses is abdominal pain. Abdominal distension and vomiting are rare symptoms [6, 7]. Other symptoms indicating an ovarian mass except acute or chronic abdominal and pelvic pain in the paediatric age group may include puberty precox, virilisation, and abnormal genital bleeding [8].

Frequent use of imaging methods enables detection of ovarian pathologies more; therefore, classification and staging of pathological conditions of the ovaries, and determination of treatment options become more important [9].

Ultrasound is the primary diagnostic tool for early diagnosis or monitoring of ovarian masses. Ultrasound provides information about dimensions, appearance and content of ovarian masses. It also helps to select the adequate therapeutic approach. Malignancy probability of ovarian masses smaller than $8 \mathrm{~cm}$, with unilateral and unilocular pattern, thin and smooth wall, without any intra abdominal fluid is less than $1 \%[10,11]$. Pure cystic ovarian masses detected through imaging tests conducted in the present study were significant for NNG ( $\mathrm{p}=0.01)$.

Malignancies of ovaries appear as complex masses with irregular wall, unidentified pattern, necrotic centres and papillary projections in the ultrasound [12]. In the present study, there was not any statistically significant difference between two groups for solid and mixed appearance detected by imaging techniques.

MRI should be preferred if no regression is detected in dimensions of ovarian masses during the control ultrasound scan after 6 to 8 weeks. CT should only be preferred for staging of histological proven masses in adolescent and paediatric age group. Preoperative pelvic MR images may change the surgical preference of paediatric patients with adnexial mass. MRI may provide valuable information when extra-ovarian origin of the mass was suspected [13]. All patients for whom CT was preferred for imaging technique were those who have referred to emergency department because of abdominal pain.

Previous studies of the literature reported that age, puberty precox, early virilisation, increase in dimensions of the ovary $(>8$ to $10 \mathrm{~cm}$ ), presence of any solid component inside the ovarian tissue, and elevation in tumour marker(s) were significant for ovarian neoplasm. Marro et al. [14] reported sensitivity of pelvic MRI in benign ovarian masses as $85.7 \%$ [14]. In the present study, sensitivity of pelvic MRI was detected as $96.1 \%$.

There are studies accepting the cut-off value of $5 \mathrm{~cm}$ for malignancy in ovarian masses. Papic et al. offered a cut-off value of $10 \mathrm{~cm}$ for dimensions of the mass in order to detect the malignancy [15]. Since $11 \%$ of malignant ovarian masses are smaller than $10 \mathrm{~cm}$ and $22 \%$ of them do not contain any solid component (complex), none of these assumptions are one hundred percent sensitive. The cut-off value for ovarian masses was accepted as $8 \mathrm{~cm}$ in the present study; there was not any statistically significant difference for large masses between two groups ( $\mathrm{p}=0.375$ ). Masses with a diameter equal to and smaller than $8 \mathrm{~cm}$ were significant for NNG.

Studies detected in the literature have reported that alfafeto-protein (AFP) and beta-HCG which were not higher in non-neoplastic ovarian masses were quite specific for neoplastic ovarian masses. However, no increase was detected in any tumour marker in $17 \%$ of the patients with malignancy; and malignancies were not excluded when no increase was detected in tumour markers. Although requirement of cytological analysis appears in case if higher tumour marker levels, an aggressive surgical procedure should never be planned due to elevation in tumour markers only. 
Papic et al. [15] reported that AFP and beta-HCG are highly associated with malignancy, and such markers are not positive in non-euplastic ovarian masses. However, other reports indicated that the rate of non-euplastic lesions varies between 3\% and 20\% along with the increase in tumour markers $[15,16]$.

Use of tumour markers for discrimination of ovarian masses is also contradictory. The literature review indicated that tumour markers were higher in $4 \%$ to $20 \%$ of benign masses. Increase of several tumour markers is detected in ovarian masses with malignant characteristics. Unnecessary aggressive surgical approach should be avoided on benign masses in consideration of malignancy in ovarian masses in the adolescent age group $[17,18]$. In the present study, negative AFP, beta-HCG, LDH and CA 125 tumour markers were found significant for NNG.

Approximately $60 \%$ of ovarian masses are treated surgically. More than $50 \%$ of surgical procedures for ovarian masses are performed laparoscopically in adolescents; and cystectomy is preferred rather than oopherectomy in majority ( $71 \%$ to $84 \%$ ) of the patients. Preservation of normal physiological development and fertility in the future, and leaving the ovarian tissue as much as possible are important for treatment of ovarian masses during childhood [19]. In the present study, cystectomy and ovarian conservative surgery were performed on 34 (54.8\%) patients; however, surgical procedure was not needed for $11(17.7 \%)$ patients. Oopherectomy was performed in $7(11.2 \%)$ patients only. Our results were consistent with the literature.

Safety of ovarian conservative procedures was proven for adolescents; and minimally invasive surgical procedures have become a gold standard treatment in the last decade. Majority of the surgeons agree on trying ovarian conservative surgery as much as possible for ovarian masses in paediatric patients [20]. Minimally invasive surgical techniques have become a surgical standard for removal of non neoplatic masses in the last decade; and many surgeons prefer laparoscopy due to shorter recovery period, decreased pain and cosmetic concerns [21,22].

Rogers et al. [23] concluded that laparoscopic approach is safer for adnexal masses with maximum diameter equal to and smaller than $8 \mathrm{~cm}$, and non-complex appearance through imaging methods in the children and adolescents [23].

Precedence of laparoscopy and laparotomy is contradication for neoplastic ovarian masses. Mayer et al. reported a case with peritoneal implantation of squamouse cell carcinoma developed after the rupture of desmoids cyst during laparoscopic surgery [24]. Conservative treatment approach should be adopted for non-neoplastic ovarian cysts as much as possible. Kathleen et al. suggested ovarian conservative strategies unless malignancy of the ovarian mass is clearly suspected [25].

Laparoscopy is a safe and efficient method for differential diagnosis and treatment of ovarian pathologies in girls with abdominal pain complaint. Torsion of the ovary should also be considered in girls if nausea and vomiting are concomitant to abdominal pain. Besides malignancy, the most common cause for oopherectomy is torsion of the ovary appeared with circulation disorder of the ovarian tissue [26].

Torsion of the ovary is an emergency case which should always be considered for differential diagnosis of a paediatric female patient presenting acute abdominal pain. It was recently proven that black-bluish macroscopic appearance of the ovary is not a real indicator for grade of ischemia; and not a valid clinical method to predict viability of the ovarian torsion [27].

The approach to ovarian masses in the children should be planned in consideration of fertilization in the future by following ontological principles. However, limited number of patients exposed to oopherectomy had a benign cytopathological diagnosis after the surgery. Oopherectomy should be considered as unacceptable in a benign ovarian mass [28].

\section{Conclusion}

There is not any reliable and proven marker that may differentiate a benign ovarian mass from a malignant ovarian mass in paediatric patients like adult population.

Preoperative risk detection of paediatric ovarian masses for any ovarian malignancy is important for determination of surgical procedure to be performed, adequate patient informing, and avoiding unnecessary procedures. A detailed medical history, physical examination, imaging methods, and adequate tumour markers should be used for preoperative evaluation of adnexal masses.

Our study has some shortcomings and limitations. Our study has been arranged retrospectively and our number of patients is small. We think that a prospective study with more patients is needed for the most appropriate approach to ovarian mass in the pediatric age group.

Disclosures: There is no conflict of interest for all authors.

\section{Acknowledgements: None.}

Funding: None.

\section{References}

1. Hermans A. Adnexal masses in children, adolescents and women of reproductive age. Adnexal Masses in Children,Adolescents, Women of Reproductive, Age. Part 3 Enschede: Ipskamp Printing. 2018; 7-92.

2. Hermans AJ, Kluivers KB, Janssen LM, et al. Adnexalmasses in children, adolescents and women of reproductive age in the Netherlands: a nationwide population-based cohort study. Gynecol Oncol. 2016; 143:93-7. https://doi.org/10.1016/j.ygyno.2016.07.096

3. Quint EH, Smith YR. Ovarian surgery in premenarchal girls. J Pediatr Adolesc Gynecol. 1999; 12:27-9. https://doi.org/10.1016/ S1083-3188(00)86617-6

4. Cass DL, Hawkins E, Brandt ML, et al. Surgery for ovarian masses in infants, children, and adolescents: 102 consecutive patients treated in a 15-year period. J Pediatr Surg. 2001; 36:693-9. https://doi.org/10.1053/jpsu.2001.22939

5. Eskander RN, Bristow RE. Adnexal masses in pediatric and adolescent females: a review of the literature. Curr Obstet Gynecol Rep. 2012; 1:25-32. https://doi.org/10.1007/s13669-011-0001-4

6. Glorieux I, Chabbart V, Rubie H, Baunin C, Gaspard MH, Guitard J, Duga I, Suc A, Puget C, Robert A. Autoimmune hemolytic anemia associated with a mature ovarian teratoma. Arch Pediatr. 1998; 5(1):41-4. https://doi.org/10.1016/S0929-693X(97)83466-5

7. Nokura K, Yamamoto H, Okawara Y, Koga H, Osawa H, Sakai K. Reversible limbic encephalitis caused by ovarian teratoma. Acta Neurol Scand. 1997; 96:367-73. https://doi.org/10.1111/j.1600-0404.1997.tb00227.x 
8. Cartault A, Ponsar C, Menendez M, Pienkowski C. Ovarian tumor and cyst in prepubertal girls: hormonal aspects. Arch Pediatr. 2008; 15(5):778-80. https://doi.org/10.1016/S0929-693X(08)71908-0

9. Morowitz M, Huff D, Von Allmen D. Epithelial ovarian tumors in children: a retrospective analysis. J Pediatr Surg. 2003; 38(3):331-5 https://doi.org/10.1053/jpsu.2003.50103

10. Heo SH, Kim JW, Shin SS, Jeong SI, Lim HS, Choi YD, et al. Review of ovarian tumors in children and adolescents: Radiologicpathologic correlation. Radio-graphics. 2014; 34:2039-55. https://doi.org/10.1148/rg.347130144

11. Oltmann SC, Garcia N, Barber R, Huang R, Hicks B, Fischer A. Can we preoperatively risk stratify ovarian masses for malignancy? J Pediatr Surg. 2010; 45:130-4. https://doi.org/10.1016/j.jpedsurg.2009.10.022

12. Epelman M, Chikwava KR, Chauvin N, Servaes S. Imaging of pediatric ovarian neoplasms. Pediatr Radiol. 2011; 41(9):1085-99. https://doi.org/10.1007/s00247-011-2128-X

13. Bazot M, Lafont C, Roussel A, Jarboui L, Nassar-Slaba J,Thomassin-Naggara I. Soft tissue characterization of the female pelvis with MRI. J Radiol. 2010; 91(4):453-64 https://doi.org/10.1016/S0221-0363(10)70060-3

14. Marro A, Allen LM, Kives SL, Moineddin R, Chavhan GB. Simulated impact of pelvic MRI in treatment planning for pediatric adnexal masses. Pediatr Radiol. 2016; 46:1249-57. https://doi.org/10.1007/s00247-016-3606-y

15. Papic JC, Finnell SM, Slaven JE, Billmire DF, Rescorla FJ, Leys CM. Predictors of ovarian malignancy in children: Overcoming clinical barriers of ovarian preservation. J Pediatr Surg. 2014; 49:144-7. https://doi.org/10.1016/j.jpedsurg.2013.09.068

16. Abid I, Zouari M, Jallouli M, Sahli S, Bouden A, Ben Abdallah R, et al. Ovarian masses in pediatric patients: A multicenter study of 98 surgical cases in Tunisia. Gynecol Endocrinol. 2018; 34:243-7. https://doi.org/10.1080/09513590.2017.1381839

17. AyhanA, Guven S, GuvenES, Kucukali T. Is there a correlation between tumor markerpanel and tumor size and histopathology in well-staged patients with borderline ovarian tumors? Acta Obstet Gyneco Scand. 2007; 86(4):484-90. https://doi.org/10.1080/00016340701226138

18. Taskinen S, Fagerholm R, Lohi J, Taskinen M. Pediatric ovarian neoplastic tumors: Incidence, age at presentation, tumor markers and outcome. Acta Obstet Gynecol Scand. 2015; 94:425-9. https://doi.org/10.1111/aogs.12598

19. Spinelli C, Buti I, Pucci V, Liserre J, Alberti E, Nencini L, et al. Adnexal torsion in children and adolescents: New trends to conservative surgical approach - our experience and review of literature. Gynecol Endocrinol. 2013; 29:54-8. https://doi.org/10.3109/09513590.20 12.705377

20. Bristow RE, Nugent AC, Zahurak ML, Khouzhami V, Fox HE. Impact of surgeon specialty on ovarian-conserving surgery in young females with an adnexal mass. J Adolesc Health. 2006; 39:411-6. https://doi.org/10.1016/j.jadohealth.2005.12.022

21. Nitke S, Goldman GA, Fisch B, Kaplan B, Ovadia J. The management of dermoid cysts a comparative study of laparoscopy and laparotomy. Isr Med Sci. 1996; 32:1177-9.

22. Maja Raicevic, Amulya Kumar Saxena, Review of Laparoscopic Management of Mature Cystic Teratoma of Ovaries in Children. $J$ Indian Assoc Pediatr Surg. 2019; 24(2):92-96. https://doi.org/10.4103/jiaps.JIAPS_246_17

23. Rogers, EM, Casadiego, CG, Lacy J, Gerstle JT, Kives S, Allen L. Preoperative risk stratification of adnexal masses: Can we predict the optimal surgical management? J Pediatr Adolesc Gynecol. 2014; 27:125-8. https://doi.org/10.1016/j.jpag.2013.09.003

24. C Mayer, D M Miller, T G Ehlen, Peritoneal implantation of squamous cell carcinoma following rupture of a dermoid cyst during laparoscopic removal. Gynecol Oncol. 2002; 84(1):180-3. https://doi.org/10.1006/gyno.2001.6484

25. Anthony N. Karnezis and Kathleen R. Cho, Preclinical Models of Ovarian Cancer: Pathogenesis, Problems, and Implications for Prevention. Clin Obstet Gynecol. 2017; 60(4):789-800. https://doi.org/10.1097/GRF.0000000000000312

26. Smail Acimi, Acute ovarian torsion in young girls. Journal of Acute Disease. 2016; 5(1):59-61. https://doi.org/10.1016/j.joad.2015.07.006

27. Nair S, Joy S, Nayar J. Five year retrospective case series of adnexal torsion. J Clin Diagn Res. 2014; 8(12):OC09-13. https://doi. org/10.7860/JCDR/2014/9464.5251

28. Didem Baskin Embleton, Betül Zengin, Ahmet Ali Tuncer, Ahmet Afşin Kundak, Evrim Özkaraca Boyacı, Salih Çetinkurşun. Followup of neonatal ovarian cysts. A retrospective cross-sectional study. J Clin Med Kaz. 2019; 3(53):38-41 https://doi.org/10.23950/18122892-JCMK-00695

29. Reddy J, Laufer MR. Advantage of conservative surgical management of large ovarian neoplasms in adolescents. Fertil Steril. 2009; 91:1941-4. https://doi.org/10.1016/j.fertnstert.2008.02.116 